\title{
Ionospheric perturbations related to the earthquake in Vrancea area on November 22, 2014, as detected by electromagnetic VLF/LF frequency signals
}

\author{
Maria Solovieva ${ }^{1}$, Alexander Rozhnoi ${ }^{1{ }^{\star}}$, Viktor Fedun ${ }^{2}$, \\ Konrad Schwingenschuh ${ }^{3}$, Masashi Hayakawa ${ }^{4,5}$ \\ ${ }^{1}$ Institute of Physics of the Earth, Russian Academy of Sciences, Moscow, Russia \\ ${ }^{2}$ University of Sheffield, Dept. of Automatic Control and Systems Engineering, Space Systems Laboratory, Sheffield, UK \\ ${ }^{3}$ Space Research Institute, Austrian Academy of Sciences, Graz, Austria \\ ${ }^{4}$ Hayakawa Institute of Seismo Electromagnetics Co. Ltd., UEC Incubation Center-508, Chofu, Tokyo, Japan \\ ${ }^{5}$ University of Electro-Communications, Chofu, Tokyo, Japan
}

\section{Article history}

Received July 12, 2015; accepted September 10, 2015.

Subject classification:

Seismic risk, Low frequency wave propagation, Earthquake precursors.

\begin{abstract}
Data from the European network of very low/low frequency (VLF/LF) receivers has been used to study the response of the lower ionosphere to the earthquake of magnitude 5.5 in Vrancea area on November 22, 2014. Negative amplitude anomalies have been observed during 3 days before the earthquake and two days after, on the $L F(45.9 \mathrm{kHz})$ signal passed above the seismic area. No perturbations have been found for the same signal in control paths during this period. Other possible influences both from above and below which can produce perturbations in the ionosphere have been taken into consideration.
\end{abstract}

\section{Introduction}

The research of the short-term transient processes in the global lithosphere-atmosphere-ionosphere coupled system using VLF (3-30 kHz) and LF (30-300 kHz) signal monitoring is advancing rapidly at present due to development of the observation networks in the seismo-active regions. Specialized networks of stations distributed in Japan and the Far East of Russia, Middle Asia and India as well as in Europe have been installed recently. The networks operate in conjunction with powerful transmitters deployed in Europe, United States, Asia and Australia.

$\mathrm{VLF} / \mathrm{LF}$ signals from navigational or time service transmitters propagate inside the earth-ionosphere waveguide and they are reflected by the $\mathrm{D}$ region of ionosphere, at an altitude of $\sim 65 \mathrm{~km}$ during daytime, and $\sim 85 \mathrm{~km}$ during nighttime. Therefore, the received signals can provide valuable information about plasma perturbations near the upper atmosphere-lower ionosphere boundary.

The regular monitoring of many years at the $\mathrm{Pa}$ cific network has established a statistical correlation between anomalies of the VLF/LF signal parameters in the nighttime and the earthquakes with $M \geq 5.5$. Seismic-related phase and amplitude anomalies were found about one week before an earthquake (mostly on 3-5 days) and one week after the event (due to aftershock activity of strong earthquakes) [Rozhnoi et al. 2004, Maekawa et al. 2006, Kasahara et al. 2008, Hayakawa et al. 2010, Hayakawa 2011, Rozhnoi et al. 2013].

In Europe, investigation of the VLF/ LF signals associated with earthquakes has begun in the University of Bari (Italy) in 2002 [Biagi et al. 2004, 2007, 2008, 2009]. The most significant result was reported from data monitoring in three VLF/LF stations - Bari, Graz and Moscow - in connection with the earthquake in L'Aquila (Italy) on April 6, 2009 [Rozhnoi et al. 2009]. Strong nighttime negative amplitude anomalies for the long propagation paths $(\sim 3000 \mathrm{~km})$ together with the shift of evening terminator for the short paths $(\sim 800-1000 \mathrm{~km})$ have been revealed during 5-6 days before the earthquake. The crossing of "seismic" paths allowed defining the real position of the earthquake epicenter.

The pre-seismic influence upon atmosphere and ionosphere is intensively studied theoretically at present. In spite of numerous papers concerning the lithosphere-atmosphere-ionosphere coupling, this subject 


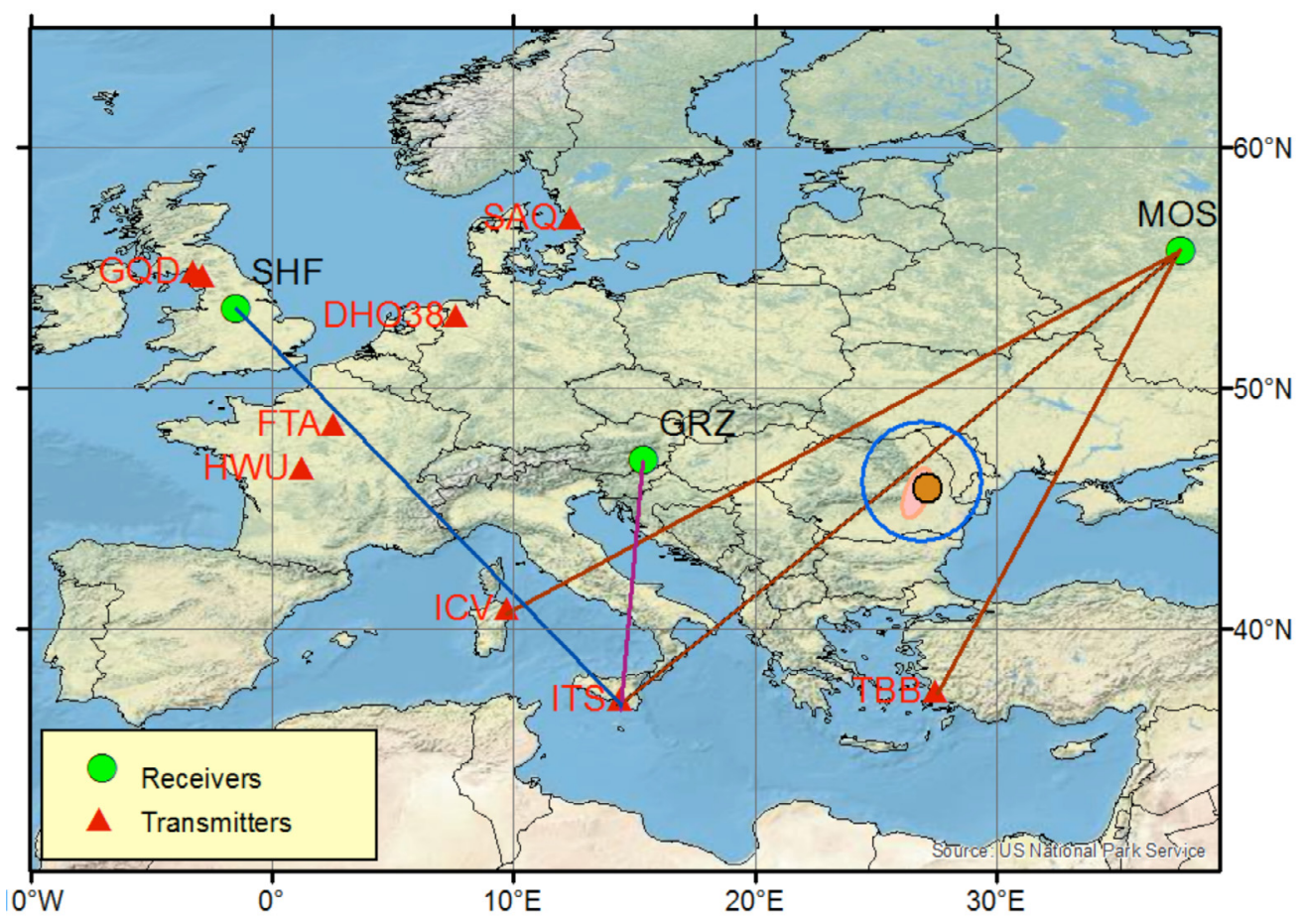

Figure 1. A map of the wave paths under analysis of the European network of VLF/LF stations. The position of the UltraMSK receivers in Moscow (MOS), Sheffield (SHF) and Graz (GRZ) and several transmitters in Europe is shown. Signals from three transmitters are analyzed in the work: ITS $(45.9 \mathrm{kHz})$, ICV $(20.27 \mathrm{kHz})$ and TBB $(26.7 \mathrm{kHz})$. Pink ellipse shows the Vrancea zone in which the strongest earthquakes occur. Solid brown circle shows the epicenter of earthquake on November 22, 2014, with M=5.5 (USGS/NEIC). The area where possible precursors of an earthquake can be found is shown by the hollow blue circle.

still needs further investigation.

It is assumed [e.g. Molchanov and Hayakawa 2008] that different kind of gases leak from the crust during the preparation stage of tectonic earthquakes over seismically active faults which leads to changes in the air temperature and density and distribution of the charged particles (due to emanation of radon). Such changes can take place in the thin near-ground layer, because of slow vertical diffusion the heavy gases and temperature variations. Possible mechanisms for energy-transport channels from the near-ground layer to the atmosphere and ionosphere are mainly divided in two groups. One possibility consists of generation of electric field or modification of background electric field [e.g. recent works from Pulinets and Ouzounov 2011, Denisenko et al. 2013, Harrison et al. 2014, Sorokin and Hayakawa 2013]. Other possibility is excitation of internal gravity waves which propagate upward and disturb the ionosphere before earthquakes [e.g. Molchanov and Hayakawa 2008, Shalimov et al. 2009, Erokhin et al. 2013]. It is impossible to select one of the models because there are not now any convincing experimental evidences supporting one or the other theory of seismo-ionospheric coupling. We can only assume that there can be several physical mechanisms responsible for seismo-ionospheric perturbation.

In Europe at present operates the South European network INFREP (International network for frontier research on earthquake precursors) which consists of eleven receivers that record the amplitude of VLF/LF signals in two frequency bands $-20-60 \mathrm{kHz}$ and $150-$ $300 \mathrm{kHz}$. The equipment is constructed by the Italian company Elettronika S.R.L. [Biagi et al. 2011].

Our receiving stations deployed both in Europe and Asia are equipment with the UltraMSK receivers (New Zealand, LF*EM Research, Ltd) which can record simultaneously the amplitude and phase of MSK (minimum shift keying) modulated signals in the frequency range $10-50 \mathrm{kHz}$ from several (10-12) transmitters. MSK signals have fixed frequencies in the narrow band $50-100 \mathrm{~Hz}$ around the main frequency and adequate phase stability. The receivers provide measurements with time resolutions ranging from $50 \mathrm{~min}$ to $60 \mathrm{~s}$. For our purpose we use sampling frequency of $20 \mathrm{~s}$.

The analysis reported in this paper in connection with the earthquake in Vrancea zone on November 22, 2014, is based on the data recorded by the three VLF/LF stations in Europe: Graz (Austria), Sheffield (U.K.) and Moscow (Russia).

\section{Data analysis and results}

The relative locations of our observing UltraMSK stations and several transmitters in Europe are plotted in Figure 1 together with the position of the epicenter of earthquake on November 22, 2014 in the Vrancea seismogenic zone. Vrancea zone is one of the most ac- 
tive seismic areas in Europe. It is situated where the southern and eastern Carpathian Mountains join (see Figure 1). Because earthquake hypocenters are concentrated within a small volume, the Vrancea zone is often described as unique. Maximum magnitude of earthquakes in this area can reach up to $M=7.0-7.8$. Foci of earthquakes are located in the crust as well as in mantle on depths $\sim 70-200 \mathrm{~km}$ [e.g. Knapp et al. 2005]. Due to the depth of the hypocenters the earthquakes can be felt as far as Moscow.

The earthquake with $\mathrm{M}=5.5$ (depth $=39 \mathrm{~km}$ ) occurred at 19:14 UT on November 22, 2014, in Vrancea area $\left(45.87^{\circ} \mathrm{N} 27.16^{\circ} \mathrm{E}\right)$ according to Geological Survey of National Earthquake Information Center of U.S. (USGS/NEIC). The hypocenter was in the crust and seismic effect from the earthquake was noticeable only in the neighboring countries: Romania, including Bucharest, on the north part of Bulgaria, in Moldova (Kishinev, Tiraspol) and at the territory of the Ukraine (Kiev, Odessa, Dnepropetrovsk). There was interruption in power supply in some areas and the cellular communications in Kishinev was out of operation for $15 \mathrm{~min}$.

Three sub-ionospheric wave paths of our network pass near or above the Vrancea zone (see Figure 1). They are: TBB $(26.7 \mathrm{kHz})$ - MOS (Moscow), ITS (45.9 $\mathrm{kHz})$ - MOS and ICV $(20.27 \mathrm{kHz})-$ MOS. The earthquake was strong enough. The radius of area where possible precursors can be found according to Dobrovolsky et al. [1979] is about $240 \mathrm{~km}$. This area is shown in Figure 1 by the hollow blue circle. As it seen from the figure only the ITS transmitter signal recorded at the Moscow station crosses the earthquake of possible precursors zone. The distance from this path to the epicenter of earthquake was about $110-115 \mathrm{~km}$ while the distances from the two other paths were about $380 \mathrm{~km}$.

Nevertheless, we checked signals variation during November 2014 in all the three wave paths. For the analysis we used a nighttime residual signal of amplitude $\mathrm{dA}: \mathrm{dA}=\mathrm{A}-\langle\mathrm{A}\rangle$; where $\mathrm{A}$ is the amplitude for the current day, and $<A>$ is the monthly averaged signals calculated using the data from undisturbed days. The results are shown in Figure 2. Five-days running averaged nighttime residual signals are represented here. The TBB transmitter in Turkey was out of operation during about ten days after November 23. The clear decrease in the amplitude of ITS transmitter signal is observed around the day when the earthquake occurred but two other signals do not reveal anomalies at that time.

For validation of the results we made an analysis of the ITS $(45.9 \mathrm{kHz})$ transmitter signal recorded at the Graz (GRZ) and Sheffield (SHF) stations during the same period. It is important to analyze the signals from

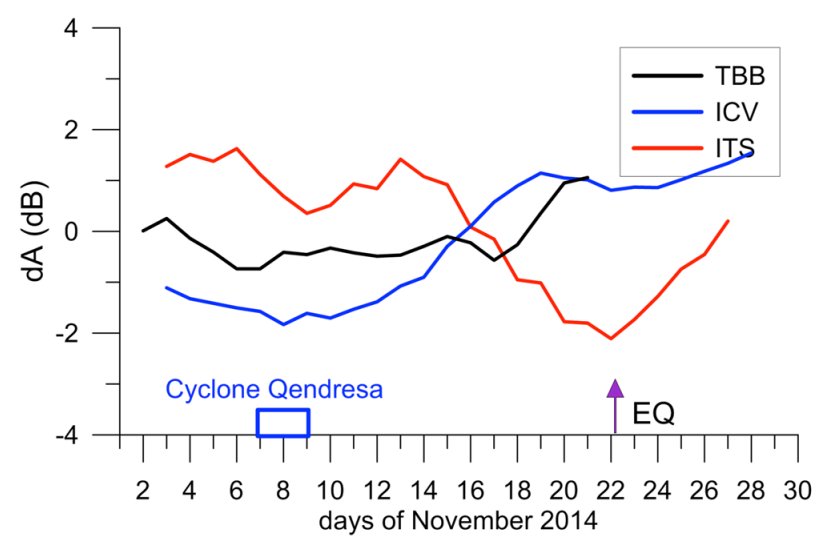

Figure 2. Five-days running averaged nighttime residual signals of the amplitude recorded in Moscow during November 2014. The amplitude of signals from three transmitters: TBB, ICV and ITS is shown. The arrow indicates the day of earthquake occurrence on November 22, 2014. Blue rectangle shows the activity of a Mediterranean Hurricane Qendresa.

the same transmitters to be sure in reliability of findings, because characteristics of the signal disturbances can be different for the signals with different frequencies.

The ITS signal recorded at the Moscow station passed over seismic area while the same signal recorded at the two other stations passed far away from the epicenter of the earthquake (see Figure 1). So, the path IST-MOS was 'seismic' path and paths ITS-GRZ (Graz) and ITS-SHF (Sheffield) were 'aseismic' control paths. A comparison of observations is shown in Figure 3. The top panel shows Dst index of magnetic activity, the next panel shows variations of atmospheric pressure in Moscow, the lower three panels show averaged in nighttime residual signals of amplitude in Graz, Sheffield and Moscow. An arrow at the bottom panel indicates the day of earthquake and horizontal blue rectangle is the period when anomalous signal was observed in Moscow. As it seen from the figure the magnetic activity was very low during this period (Dst $\sim 0$ ), so that the observed anomalies cannot be attributed to the geomagnetic environment. Not very strong proton burst (in the range $0.6-4.2 \mathrm{MeV}$ ) was observed on November 2-3 and rather weak relativistic electron flux was registered on November 15-16 (EPS/ GOES measurements). No outer-zone particles fluxes were observed during other days of November.

Another factor that can influence on the behavior of the VLF/LF signals is fluctuations of the atmospheric pressure [Rozhnoi et al. 2014]. Strong decrease in atmospheric pressure was recorded in Moscow at the beginning of November. It could result in decrease of the signal in Moscow detected on November 7-11. We have to note that strong cyclones propagated through Europe during the first ten days or so of November. Variations of the ITS signal at the Sheffield station at the beginning of the month coincide with variations of 

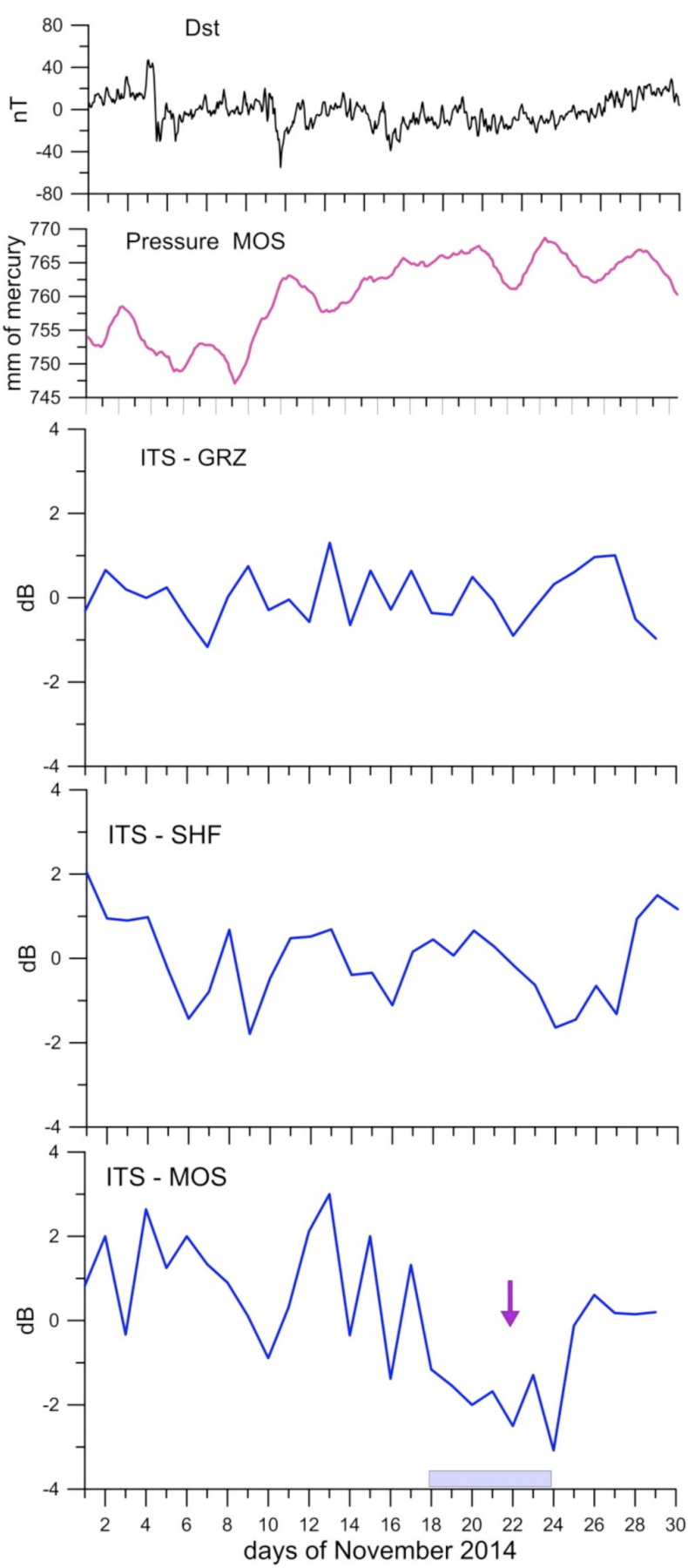

Figure 3. The measurements of the ITS transmitter signal at three VLF/LF stations during November 2014. The top panel shows Dst index of magnetic activity, the next panel shows variations of atmospheric pressure in Moscow, the lower three panels show averaged for nighttime the residual signals of amplitude in Graz, Sheffield and Moscow. An arrow at the bottom panel indicates the day of earthquake and horizontal blue rectangle is the period when anomalous signal was observed in Moscow.

atmospheric pressure recorded in the Middle England. Strong cyclone raged in Germany with wind velocity up to $150 \mathrm{~km} / \mathrm{h}$. Mediterranean cyclone brought strong precipitation to Italy which led to flood. The cyclone which formed on November 7 near the North Africa coast and moved afterwards towards Sicily was such strong as a tropical cyclone. Such strong cyclone activ- ity in Europe can explain decrease in the ITS signal at the first ten days of the month. Especially strong decrease was detected in the ICV transmitter signal (see Figure 2). The weather was much better during the second half of November (as seen from the pressure data in Moscow) and could not cause the observed anomalies in the signal.

Figure 4 shows an example of amplitude (left) and phase (right) of the ITS transmitter signal recorded during local night in Sheffield, Graz and Moscow (top to bottom) on November 21, 2014 (red line) together with the monthly averaged signal (brown). The latter was calculated using data from undisturbed days. Only the amplitude of the signal in Sheffield is shown because the phase data was not good enough in November at this station. It is clear that the measurements of amplitude and phase in Graz and Sheffield (control paths) closely follow the quiet day measurements. The signal propagating along the path ITS-MOS, however, exhibits a significant decrease in amplitude (about $10 \mathrm{~dB}$ ) during the period from about $11 \mathrm{pm}$ to $01 \mathrm{am}$ UT. At the same time the phase variations of up to 50 degrees relative to the averaged signal are observed at the Moscow station. The similar anomalies were observed at the Moscow stations during 3 days before the earthquake and two days after it.

Beside the method of 'bay-like' nighttime phase and amplitude anomalies and its derivative - method of residual nighttime VLF/LF signal which was described above -, another, terminator time (TT) method was used for 'seismic' and control paths. The method is based on determination of the characteristics minimums of phase and amplitude daily variations during sunset and sunrise, and it is widely used now to identify possible seismo-ionospheric effects. This method was developed by Hayakawa and Molchanov in analysis of the Kobe earthquake ( $M=7.2)$ [Hayakawa et al. 1996]. They found an anomalous shift in fluctuations of TT 3 days before the main shock of earthquake. After the first resuls, the method was used in analysis of many earthquakes. The method and theoretical investigations are described in many details in book of Molchanov and Hayakawa [2008]. The authors conclude that '... there is dependence on number of modes efficiently involved into the modal superposition, supposing that all the propagating modes $(n \leq 5)$ could be intensified. So it can be applied only for the more or less short wave paths $(\mathrm{D}<1000-2000 \mathrm{~km}) \ldots$. . In present case we have more long 'seismic' path $(\sim 3000 \mathrm{~km})$. The results of analysis for amplitude variations in 'seismic' and control paths are shown in Figure 5. The analysis was made for morning terminator which in this season in middle latitude in Europe moves gradually. Evening terminator 


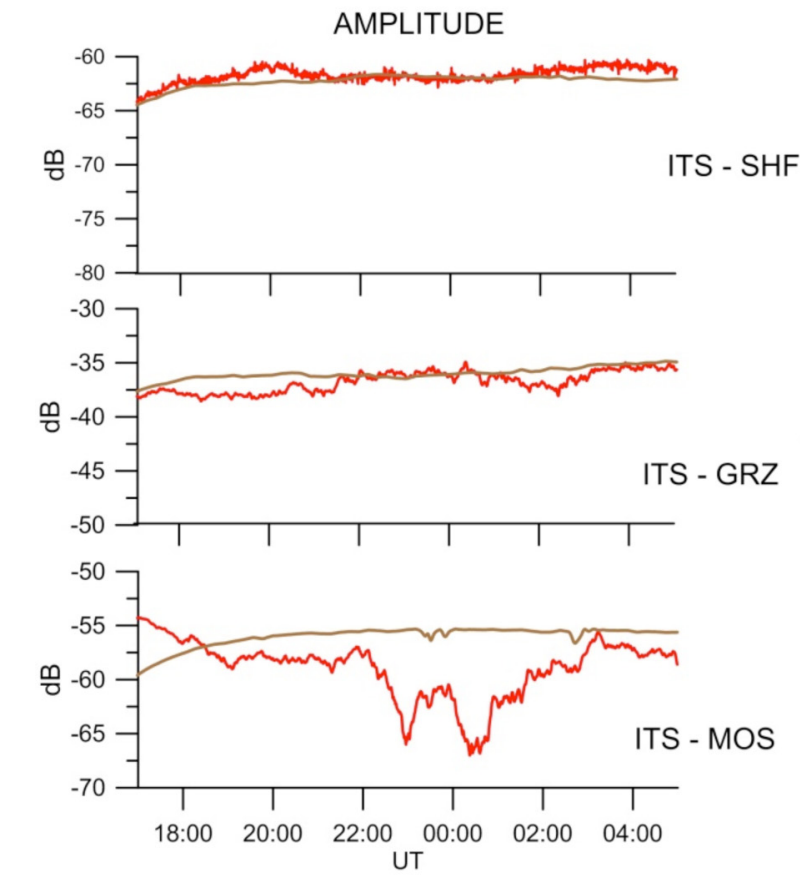

PHASE
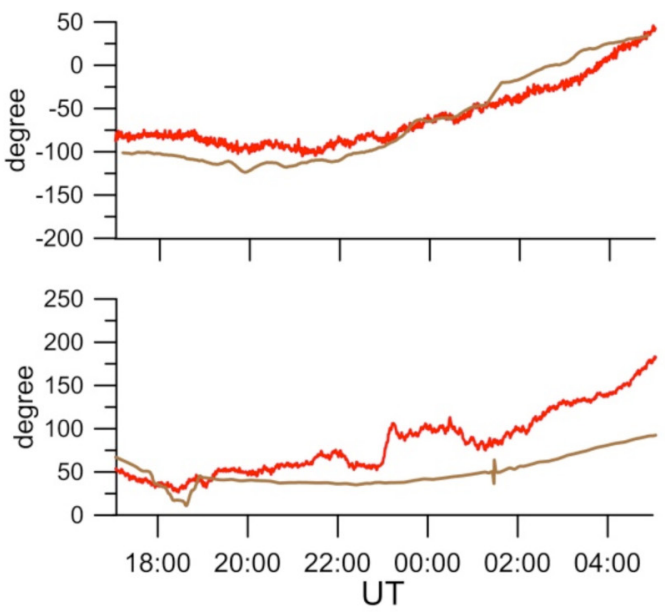

Figure 4. An example of amplitude (left) and phase (right) of the ITS transmitter signal recorded during local night in Sheffield, Graz and Moscow (top to bottom) on November 21, 2014 (red line) together with monthly averaged signal (brown).

practically doesn't change its position. For 'seismic' ITSMOS path we see anomalous shift in the morning minimum exceeding $2 \sigma$ level on $6 \mathrm{~min}$, two days before the earthquake. While the variations of morning minimum in the amplitude of LF signal in the control path don't deviate noticeably from the normal position of terminator, strong variations of the LF morning minimum are observed around time of the earthquake in the 'seismic' path. Although the results are not very remarkable (maybe, due to the length of the path) they, nevertheless, confirm possible seismo-ionospheric effects revealed by the method of 'bay-like' nighttime signal anomalies.

The spectra of the filtered phase (in the range of periods from 1 to 60 minutes) of the nighttime ITS signal recorded at the Moscow station on possible seismoinduced anomalous day of November 21 together with the spectra of undisturbed signals recorded at the Moscow station on November 14 and Graz station on November 21 are shown in Figure 5. The spectra of undisturbed signals are very similar for the two stations with maximum of spectral density about $40 \mathrm{~min}$. The spectrum of the seismo-induced anomalous signal, however, shows a main maximum corresponding to wave period of $30 \mathrm{~min}$ and also contains waves with shorter periods in the range $20-30 \mathrm{~min}$, which corresponds to the range of internal gravity waves periods. The shift of the signal spectra of the seismo-induced anomalous days towards shorter periods in comparison with that of quiet or magnetic-disturbed signals has been found in our previous studies for strong earthquakes in Eu-

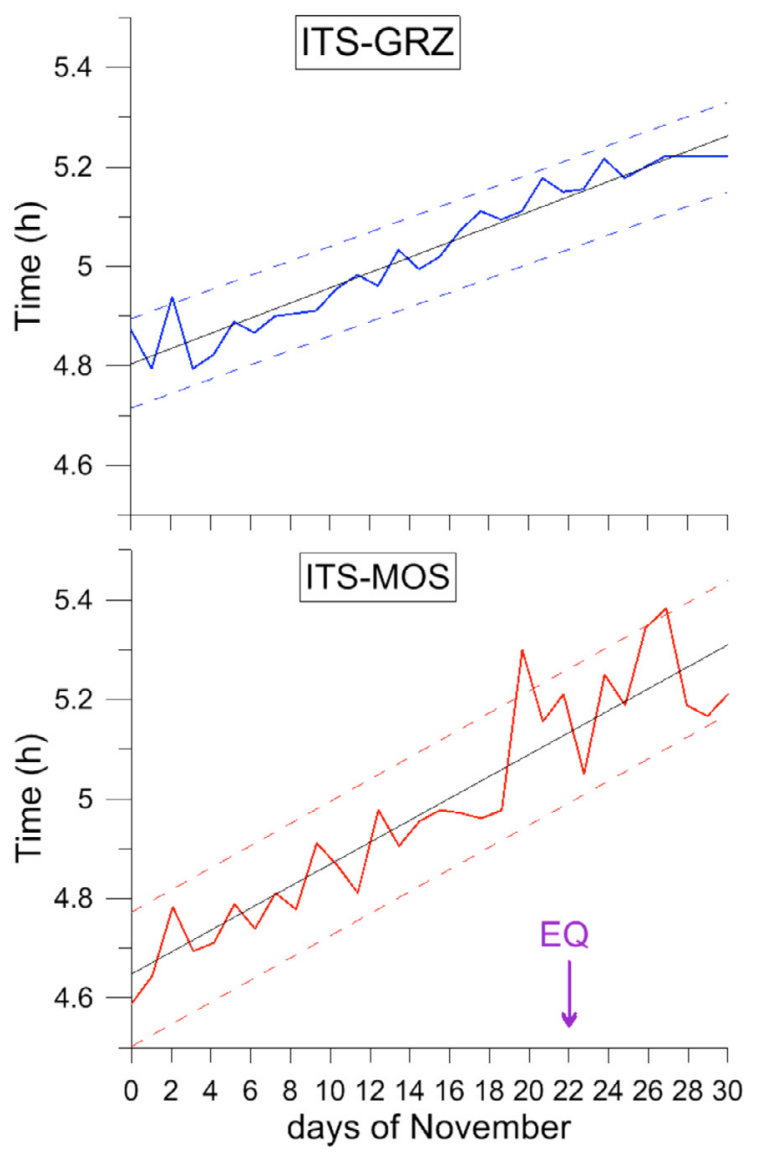

Figure 5. In the upper panel sunrise terminator times for ITS-GRZ (control path, blue line), in the bottom panel sunrise terminator times for ITS-MOS ('seismic' path, red line). Dash lines show 2 standard deviations relative the real terminator at the altitude $100 \mathrm{~km}$. The vertical axis indicates the time in hours from the midnight. The arrow in the bottom panel shows the occurrence of the earthquake on November 22, 2014. 


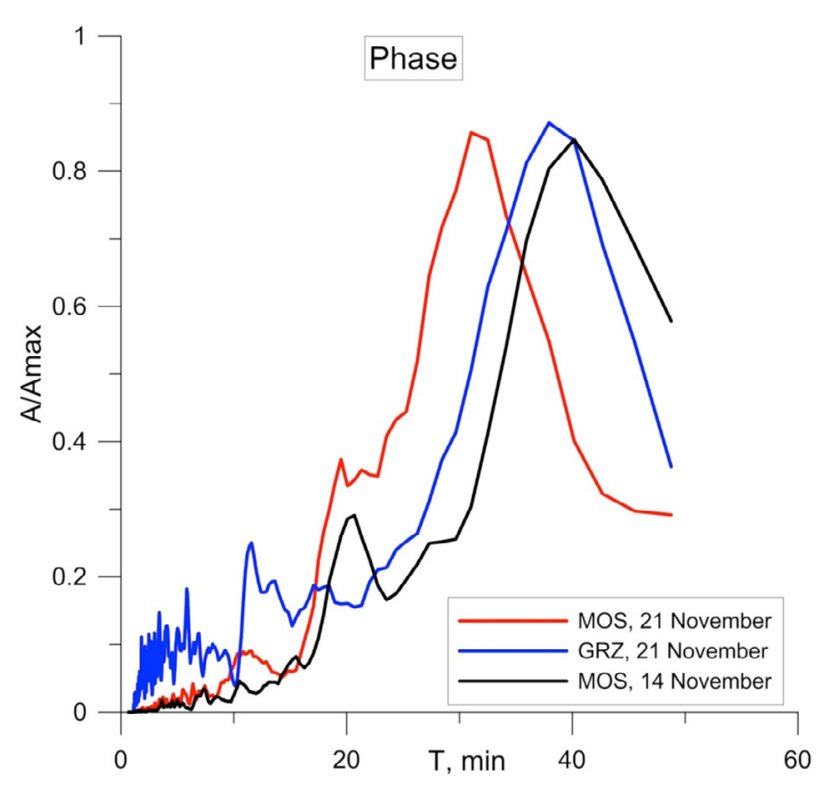

Figure 6. Averaged (3 days running) normalized spectra of the phase of ITS signal recorded at the Moscow station on November 14 and 21 and Graz station on November 21. Spectra were calculated for nighttime signal filtered in the range of periods from 1 to 60 minutes.

rope and the Far East region [Rozhnoi et al. 2012]. This result can be considered as some corroboration that the possible mechanism for energy penetration from the earthquake origin, through the atmosphere, and into the ionosphere is based on the excitation and upward propagation of internal gravity waves.

\section{Conclusion}

The analysis of the VLF/LF signals during November 2014 have revealed perturbations of the nighttime subionospheric LF signal passing above the epicentre of earthquake occurred on November 22, 2014, in the Vrancea area. Negative amplitude anomalies have been observed during 3 days before the earthquake and two days after it at the analysis of the nighttime residual signal amplitude. TT method have revealed anomalous shift in the LF signal morning minimum two days before the earthquake and strong variations of the minimum around the time of the earthquake.

The result has been confirmed by comparison of data measurements in control 'aseismic' paths. Other possible influences both from above (geomagnetic activity, proton bursts and relativistic electron fluxes) and below (cyclonic activity) which can produce perturbations in the ionosphere were taken into consideration.

The recent development of the observation systems in Europe, Asia and the Far East can provide useful information on the properties and position of the perturbation region in connection with seismic activity. The use of a network of observation makes it possible to separate the local VLF/LF perturbations connected with earthquakes from large-scale or global anomalies related to atmospheric circulation and space weather conditions. By utilising multi-station observations it is possible to determine the area of an impending earthquake.

\section{Data and sharing resources}

Earthquake catalog used in this paper can be found in the site:

http: / / neic.usgs.gov/neis/epic/epic_global.html

Dst data were taken from:

http: / / swdcwww.kugi.kyoto-u.ac.jp/dstdir/index.html

Fluxes of out-space particles (electrons, protons) were taken from:

http: / / spidr.ngdc.noaa.gov/spidr/

Data on atmospheric pressure were obtained from: http: / / rp5.ru/.

\section{References}

Biagi, P.F., R. Piccolo, L. Castellana, T. Maggipinto, A. Ermini, S. Martellucci, C. Bellecci, G. Perna, V. Capozzi, O. Molchanov, M. Hayakawa and K. Ohta (2004). VLF-LF radio signals collected at Bari (South Italy): a preliminary analysis on signal anomalies associated with earthquakes, Nat. Hazards Earth Syst. Sci., 4, 685-689.

Biagi, P.F., L. Castellana, T. Maggipinto, G. Maggipinto, A. Minafra, A. Ermini, V. Capozzi, G. Perna, M. Solovieva, A. Rozhnoi, O. Molchanov and M. Hayakawa (2007). Decrease in the electric intensity of VLF/LF radio signals and possible connections, Nat. Hazards Earth Syst. Sci., 7, 423-430.

Biagi, P.F., L. Castellana, T. Maggipinto, D. Loiacono, V. Augelli, L. Schiavulli, A. Ermini, V. Capozzi, M.S. Solovieva, A.A. Rozhnoi, O.A. Molchanov and M. Hayakawa (2008). Disturbances in a VLF radio signal prior the $M=4.7$ offshore Anzio (central Italy) earthquake on 22 August 2005, Nat. Hazards Earth Syst. Sci., 8, 1041-1048.

Biagi, P.F., L. Castellana, T. Maggipinto, G. Maggipinto, A. Minafra, A. Ermini, O. Molchanov, A. Rozhnoi, M. Solovieva and M. Hayakawa (2009). Anomalies in VLF radio signals related to the seismicity during November-December 2004: A comparison of ground and satellite results, Phys. Chem. Earth, 34 (6-7), 456-463.

Biagi, P.F., T. Maggipinto, F. Righetti, D. Loiacono, L. Schiavulli, T. Ligonzo, A. Ermini, I.A. Moldovan, A.S. Moldovan, A. Buyuksarac, H.G. Silva, M. Bezzeghoud and M.E. Contadakis (2011). The European VLF/LF radio network to search for earthquake precursors: setting up and natural/man-made disturbances, Nat. Hazards Earth Syst. Sci., 11, 333341; doi:10.5194/nhess-11-333-2011. 
Denisenko, V.V., M. Ampferer, E.V. Pomozov, A.V. Kitaev, W. Hausleitner, G. Stangl and H.K. Biernat (2013). On electric field penetration from ground into the ionosphere, J. Atm. Sol.-Terr. Phys., 102, 341-353; doi:10.1016/j.jastp.2013.05.019.

Dobrovolsky, I.R., S.I. Zubkov and V.I. Myachkin (1979). Estimation of the size of earthquake preparation zones, Pure Appl. Geophys., 117, 1025-1044.

Erokhin, N.S., L.A. Mikhailovskaya and S.L. Shalimov (2013). Conditions of the propagation of internal gravity waves through wind structures from the troposphere to the ionosphere, Izv. Atmos. Ocean. Phy+, 49 (7), 732-744; doi:10.1134/S0001433813070025.

Harrison, R.G., K.L. Aplin and M.J. Rycroft (2014). Brief Communication: Earthquake-cloud coupling through the global atmospheric electric circuit, Nat. Haz. Earth Sys. Sci., 14 (4), 774-777; doi:10.5194/nh ess-14-773-2014.

Hayakawa, M., O.A. Molchanov, T. Ondoh and E. Kawai (1996). Precursory Signature of the Kobe Earthquake on VLF Subionospheric Signal, J. Atmos. Electr., 16 (3), 247-257.

Hayakawa, M., Y. Kasahara, T. Nakamura, Y. Hobara, A. Rozhnoi, M. Solovieva and O.A. Molchanov (2010). On the correlation between ionospheric perturbations as detected by subionospheric VLF/LF signals and earthquakes as characterized by seismic intensity, J. Atmos. Sol.-Terr. Phy., 72, 982-987.

Hayakawa, M. (2011). Probing the lower ionospheric perturbations associated with earthquakes by means of subionospheric VLF/LF propagation, Earthquake Sci., 24 (6), 609-637.

Kasahara, Y., F. Muto, T. Horie, M. Yoshida, M. Hayakawa, K. Ohta, A. Rozhnoi, M. Solovieva and O.A. Molchanov (2008). On the statistical correlation between the ionospheric perturbations as detected by subionospheric VLF/LF propagation anomalies and earthquakes, Nat. Hazards Earth Syst. Sci., 8, 653-656.

Knapp, J.H., C.C. Knapp, V. Raileanu, L. Matenco, V. Mocanu and C. Dinu (2005). Crustal constraints on the origin of mantle seismicity in the Vrancea Zone, Romania: The case for active continental lithospheric delamination, Tectonophysics, 410, 311-323.

Maekawa, S., T. Horie, T. Yamauchi, T. Sawaya, M. Ishikawa, M. Hayakwa and H. Sasaki (2006). A statistical study on the effect of earthquakes on the ionosphere, based on the subionospheric LF propagation data in Japan, Ann. Geophsicae, 24, 2219-2225.

Molchanov, O.A., and M. Hayakawa (2008). Seismo Electromagnetics and Related Phenomena: History and Latest results, TERRAPUB, Tokyo, $189 \mathrm{p}$.

Pulinets, S., and D. Ouzounov (2011). Lithosphere-At-
mosphere-Ionosphere Coupling (LAIC) model - An unified concept for earthquake precursors validation, J. Asian Earth Sci., 41, 371-382; doi:10.1016/j.js eaes.2010.03.005.

Rozhnoi, A., M.S. Solovieva, O.A. Molchanov and M. Hayakawa (2004). Middle latitude LF (40 kHz) phase variations associated with earthquakes for quiet and disturbed geomagnetic conditions, Phys. Chem. Earth, 29, 589-598.

Rozhnoi, A., M. Solovieva, O. Molchanov, K. Schwingenschuh, M. Boudjada, P.F. Biagi, T. Maggipinto, L. Castellana, A. Ermini and M. Hayakawa (2009). Anomalies in VLF radio signals prior the Abruzzo earthquake $(M=6.3)$ on 6 April 2009, Nat. Hazards Earth Syst. Sci., 9, 1727-1732.

Rozhnoi, A., M. Solovieva, P.F. Biagi, K. Schwingenschuh and M. Hayakawa (2012). Low frequency signal spectrum analysis for strong earthquakes, Annals of Geophysics, 55 (1), 181-186; doi:10.4401/ag-5076.

Rozhnoi, A., M. Solovieva and M. Hayakawa (2013). VLF/LF signals method for searching of electromagnetic earthquake precursors, In: M. Hayakawa (ed.), Earthquake Prediction Studies: Seismo Electromagnetics, TERRAPUB, Tokyo, 31-48.

Rozhnoi, A., M. Solovieva, B. Levin, M. Hayakawa and V. Fedun (2014). Meteorological effects in the lower ionosphere as based on VLF/LF signal observations, Nat. Hazards Earth Syst. Sci., 14, 2671-2679; doi:10.5194/nhess-14-2671-2014.

Shalimov, S., T. Ogawa and Y. Otsuka (2009). On the gravity wave-driven instability of E layer at mid-latitude, J. Atmos. Sol.-Terr. Phy., 71 (17), 1943-1947; doi:10.1016/j.jastp.2009.08.004.

Sorokin, V., and M. Hayakawa (2013). Generation of Seismic-Related DC Electric Fields and LithosphereAtmosphere-Ionosphere Coupling, Mod. Appl. Sci., 7 (6), 1-25; doi:10.5539/mas.v7n6p1.

Corresponding author: Alexander Rozhnoi, Institute of Physics of the Earth, Russian Academy of Sciences, Moscow, Russia; email: rozhnoi@ifz.ru.

C 2015 by the Istituto Nazionale di Geofisica e Vulcanologia. All rights reserved. 